\title{
BREAST FEEDING AND POSTNATAL CYTOMEGALOVIRUS TRANSMISSION IN PRETERM NEWBORNS
}

\author{
M. Marçal ${ }^{1}$, A.R. Campos ${ }^{2}$, S. Prado ${ }^{1}$, S. Candeias ${ }^{1}$, M. Aguiar ${ }^{1}$, M. Tuna ${ }^{1}$, O. Campos ${ }^{2}$, P. Paixão ${ }^{2}$, T. \\ Marques $^{2}$ \\ ${ }^{I}$ Unidade de Neonatologia, Hospital São Francisco Xavier - Centro Hospitalar de Lisboa Ocidental, \\ ${ }^{2}$ Faculdade de Ciências Médicas de Lisboa, Lisboa, Portugal
}

Postnatal cytomegalovirus (CMV) infections can cause severe illness in premature newborns. The main source of infection is breast milk. The aim of this study was the determination of the rate of transmission from CMV seropositive mothers and the clinical consequences.

We studied mother-newborn pairs in preterm newborns under 35 weeks of gestational age. For CMV detection in mother's milk and children's urine, a real-time PCR technique was used (samples in first and sixth weeks).

To date 19 seropositive mothers-newborn pairs were studied (four with total results available). Eight milk specimens and one urine were positive in the first week (8/19- $42 \%$ and $1 / 21-4.8 \%)$.

The four milk specimens collected in the sixth week confirmed the first results. The urine specimens also confirmed the first results, except for one newborn, which urine became positive and had neutropenia.

These results suggest that CMV reactivation in mother's milk can be very common, since almost half of the mothers eliminated CMV at the end of the first week, well before the expected peak of excretion, between $4^{\text {th }}$ and $8^{\text {th }}$ weeks. More results are needed before any conclusion can be made about the utility of this screening in the premature population.

These preliminary results support the continuation of this study, extending the period of time for milk and urine collections and for the clinical follow-up of infected infants, in order to fulfill the purpose of the project, determination of the rate of transmission of CMV by breastfeeding to premature newborns and its the clinical consequences. 